\title{
Considerações sobre a abordagem de cultura em teorias de aquisição de linguagem e seus desdobramentos para o processo de ensino- aprendizagem de língua inglesa
}

\author{
Guilherme Jotto Kawachi \\ Universidade Estadual de Campinas (Unicamp)
}

\begin{abstract}
Resumo
O objetivo deste trabalho é apresentar reflexões sobre a possibilidade de abordagem de aspectos culturais em três teorias de aquisição de linguagem: behaviorismo, inatismo e sociointeracionismo. Inicialmente, descrevo (brevemente) o momento sócio-histórico contemporâneo, focalizando as frequentes relações de intercâmbio cultural entre pessoas dos mais diversos países. Esses contatos se dão nos mais variados âmbitos e, permeados pelas demandas da pós-modernidade e globalização que vivemos, ocorrem invariavelmente em Língua Inglesa (LI). As interações entre representantes de nações distintas são muitas vezes permeadas por pressupostos socioculturais contrastantes. Nesse sentido, enfatizo a necessidade de estudos que avaliem a abordagem de cultura (do aprendiz e do estrangeiro) no processo de ensino-aprendizagem de línguas estrangeiras (LE). Apresento, posteriormente, conceitos básicos referentes às três teorias de aquisição de linguagem mencionadas, e teço considerações acerca da possibilidade de orientação na cultura-alvo (BARBOSA, 2009) em cada uma das teorias.
\end{abstract}

Palavras-chave: cultura; teoria de aquisição de linguagem

\begin{abstract}
The objective of this paper is to present some reflections on the possibility of teaching culture using three language acquisition theories: behaviorism, inatism, and sociointeracionism. First, I describe the contemporary sociohistorical moment in which we find ourselves, focusing on frequent cultural exchanges between people from diverse countries. These intercultural exchanges occur in several areas, and, with the demands of the post-modern era and globalization as their historical background, conversation is usually conducted in English. Interaction between people from different nations is frequently influenced by contrastive cultural backgrounds, which may lead to cultural misunderstandings and conflicts. Therefore, I emphasize the need to develop more studies that evaluate the teaching of (native and target) culture in the teaching-learning process. Finally, I present basic concepts regarding the three theories aforementioned, and I comment on the possibility of leading students to what has been called orientation in the target-culture (BARBOSA, 2009).
\end{abstract}

Key-words: culture; language acquisition theories

\section{INTRODUÇÃOO}


O cenário atual de intensa globalização - delineado, principalmente, pela efervescência tecnológica - é composto por diversos aspectos que abrigam os reflexos de um mundo multifacetado: os âmbitos político, social, econômico, comercial, entre outros. Nessa conjuntura, existe a necessidade de contato entre pessoas provenientes tanto de contextos muito distintos quanto de culturas bastante similares, para que se desenvolvam consensos acerca de princípios e valores referentes a diversos assuntos.

Sob essa perspectiva, encontros entre pessoas de culturas variadas - portanto, encontros interculturais - assumem papel fundamental nos rumos de acordos, diálogos e conversas entre representantes de países diferentes. É através desses relacionamentos que visões sócio-políticas (e muitas outras) são expressas e negociadas, constituindo, assim, situações fundamentais para o prosseguimento da diplomacia entre os povos, como afirma Tannen (1986:11): “O destino da Terra depende de comunicação intercultural." 1 .

Partindo, então, da premissa de relevância dessas instâncias comunicativas, é necessário refletirmos sobre o papel que a linguagem exerce nesse contexto: é através dela que argumentos são emitidos e rebatidos; posições são defendidas; conceitos são apresentados ou, em suma, mensagens são comunicadas. É evidente, portanto, que a língua não é estanque; no âmbito mais abrangente da linguagem e, considerando-se sua natureza social, ela é um fenômeno vivo, construído na relação dialógica entre os interlocutores (como estudou Bakhtin), por meio do qual cidadãos dos mais distintos polos se comunicam.

Tendo em mente os frequentes intercâmbios culturais "exigidos" pelas condições da era pós-moderna, a Língua Inglesa (LI) encontra-se em posição hegemônica no que concerne aos encontros interculturais; isto é: interações entre pessoas de contextos sócio-histórico-culturais distintos geralmente ocorrem em LI. Além disso, ainda que seja vista sob uma óptica de imperialismo linguístico ${ }^{2}$, seu papel em quaisquer situações nas quais existam pessoas de diferentes países é fundamental.

A relevância da LI como língua franca atualmente justifica a demanda por pesquisas que busquem investigar os contextos em que se dá o processo de ensino-

\footnotetext{
${ }^{1}$ Tradução nossa. "The fate of the earth depends on cross-cultural communication".

${ }^{2}$ Não discordamos da possível visão referente ao imperialismo da Língua Inglesa, especialmente quando em comparação à posição de línguas e grupos minoritários em contextos de bilinguismo, diglossia, multiculturalismo. Ressaltamos, na verdade, que a LI é representativa do poder hegemônico das línguas e do mundo ocidental como um todo, em relação aos grupos marginalizados cujas línguas e dialetos invariavelmente sucumbem às relações de poder que os envolve. Entretanto, não discutiremos essas questões neste trabalho. Sugerimos a leitura de Canagarajah, R. (2005). Resisting Linguistic Imperialism in English, entre outros autores.
} 
aprendizagem dessa língua. Estudos que verifiquem as teorias que perpassam as aulas de LI fazem-se necessários, portanto, de forma a propiciar uma visão geral - e ao mesmo tempo apurada - da maneira como essa língua está sendo abordada, o que influenciará o uso da língua inglesa como língua estrangeira (LE) em interações (inter)culturais.

Este trabalho tem como objetivo, portanto, traçar um estudo introdutório sobre algumas teorias de aquisição de linguagem ${ }^{3}$ visando analisar seus alcances e limites no cenário de ensino de LI no atual mundo globalizado.

Tanto em conversações "face-a-face" quanto em outras interfaces de interação (sejam elas orais, escritas, online), os pressupostos culturais dos interlocutores estão sempre presentes, mesmo apesar de eles se comunicarem por meio de uma língua "em comum" (LI, nesse caso). É necessário, portanto, que tanto alunos quanto professores de LI sejam / estejam sensíveis à existência de diferentes traços culturais na interação para que problemas de uso da linguagem possam ser ponderados e discutidos - e não originem estereótipos, como comumente ocorre.

Para tanto, pretendo, também, verificar a possibilidade de abordagem de aspectos culturais em algumas teorias de aquisição de linguagem, por acreditar que língua e cultura são indissociáveis, já que esta (a cultura) é simbolicamente manifestada por meio de linguagem. Considerando que cultura é expressa por meio de linguagem, e que a linguagem não está separada do sujeito, cultura e língua não podem, portanto, ser fragmentadas (Bolognini, 1998).

Neste trabalho, concordo com o conceito de cultura apresentado por Da Matta (1994:17): “(...) a palavra cultura exprime precisamente um estilo, um modo e um jeito (...) de fazer as coisas.", embora, é válido ressaltar, reconheça a vasta gama de

\footnotetext{
${ }^{3}$ É necessário ressaltar que, no campo de estudos da linguagem (e nas disciplinas que o permeiam), os termos "aquisição" e "aprendizagem" não são considerados sinônimos. O primeiro é frequentemente associado ao processo vivido por crianças no desenvolvimento de sua língua materna e / ou em contextos de imersão, nos quais o uso de uma LE (ou L2) se faz necessário; nesse sentido, a língua é adquirida "naturalmente", isto é, sem, necessariamente, haver interferência da educação escolar. Em contrapartida, "aprendizagem" é um termo pertinente aos contextos de sala de aula, nos quais o aluno é levado a observar, compreender e utilizar uma língua por meio de práticas didático-pedagógicas; nesse caso, o aprendizado da LE é considerado o objetivo do processo de ensino-aprendizagem de línguas. Opto, neste trabalho, pelo uso da expressão "teorias de aquisição de linguagem", por dois motivos: primeiro, pois essa construção me parece recorrente na literatura da área e é, nesse sentido, carregada de muitos significados (relevantes) já legitimados; além disso, muitas das teorias da psicologia, da educação e da linguística que discuto neste texto foram, originalmente, desenvolvidas com foco na língua materna. Parece-me, portanto, mais coerente que essa expressão seja adotada. Devo ressaltar, todavia, que não é o objetivo deste artigo discutir as diferenças entre "aquisição" e "aprendizagem"; faço, neste ponto, apenas um esclarecimento terminológico breve. Há uma vasta gama de teóricos que estudam essa questão, mais reconhecidamente Krashen, cuja leitura recomendo.
} 
definições acerca desse conceito. Por questões de tempo e espaço, entretanto, opto por não apresentá-las neste trabalho.

O modo e / ou jeito de fazer as coisas, como revela Da Matta (1994), corroboram a relevância da reflexão sobre a linguagem para o conceito de cultura. É fundamental, assim, que as teorias de aquisição de linguagem sejam ricas a ponto de comportarem a noção de cultura no processo de ensino-aprendizagem de línguas.

\section{TEORIAS DE AQUISIÇÃO DE LINGUAGEM: UMA VISÃO GERAL}

Em instâncias comunicativas em diversos âmbitos, compostas por representantes das mais variadas culturas, a língua estrangeira, especialmente a língua inglesa, assume posição fundamental - já que é através da linguagem (verbal ou não-verbal) que mensagens são comunicadas. Entendo que a interação intercultural, comumente pautada pela LI, envolve, muitas vezes, pressupostos culturais distintos que se consubstanciam nos discursos dos interlocutores envolvidos na cena enunciativa, o que pode acarretar problemas de uso da língua.

Segundo Figueiredo (1997:15), “É a linguagem que faz com que o homem possa pensar, refletir, exprimir-se, interagindo com os outros e com o que há a sua volta (...)”. Dada a importância atribuída à linguagem em quaisquer encontros comunicativos, é essencial que se investigue a maneira como a reconhecida "língua franca", a LI, é ensinada. Não obstante, faz-se necessário avaliar as teorias de aquisição de linguagem em relação ao seu objetivo maior: a língua está sendo ensinada de maneira significativa, visando evitar (e visando preparar os alunos para) problemas e "quebras" na comunicação?

Entendo que mal-entendidos em situações comunicativas podem ser decorrentes de inúmeras causas, constituindo, às vezes, acasos e eventualidades. Acredito, todavia, que as abordagens e metodologias de ensino de línguas têm influência na (trans)formação de alunos capazes de obterem sucesso na comunicação.

Para Figueiredo (1997:15): “(...) a língua é o conjunto das palavras e expressões usadas por um povo e o conjunto de regras da sua gramática, que é concretizada pelo discurso de seus falantes, por meio da interação entre eles”. Assim, considerando que o foco do ensino de LE é, grosso modo, a construção de discursos significativos, críticos e inteligíveis, restrinjo-me às teorias de aquisição de linguagem mais difundidas nas 
pesquisas em Linguística Aplicada e nas ciências de contato (linguística, psicologia, educação, e outras).

De acordo com Richards e Rodgers (2001), as abordagens de ensino de línguas estão atreladas a dois pilares: teorias de língua (geralmente estudadas por linguistas) e teorias de aprendizagem de línguas (comumente investigadas por pesquisadores da psicologia). Assim, ainda que, originalmente, cada teoria tenha surgido em um determinado campo, é válido avaliar ambos os aspectos linguísticos e psicolinguísticos das teorias que abordamos neste trabalho.

As teorias de ensino de LE possuem, muitas vezes, semelhanças estruturais com aquelas desenvolvidas para a aquisição de língua materna. Por este ponto de vista, podemos citar três paradigmas acerca da aquisição de língua materna ou estrangeira. Para Skinner ${ }^{4}$, a aquisição de uma língua se dá por meio de condicionamento de comportamentos, adquirida através da construção e manutenção de hábitos. Por isso, essa teoria recebe o nome de behaviorismo.

O behaviorismo é fundamentado na teoria da psicologia comportamental e, no ensino de línguas, é atrelado aos princípios da linguística estrutural (Larsen-Freeman, 2000). A linguística estrutural, reacionária à gramática tradicional, priorizava (quando seus estudos, originalmente, se desenvolveram) a linguagem oral. Essa ênfase na fala, somada aos princípios behavioristas (repetição, imitação, formação de hábitos) é refletida nas técnicas do método audiolingual, sustentado pelas teorias de língua e de aprendizagem descritas.

Chomsky (1969) é o maior expoente da teoria do inatismo, segundo a qual os seres humanos possuem uma predisposição inata para aprender uma língua. Dessa forma, os sujeitos possuem capacidade cognitiva de internalizar regras e suas sistemáticas. Lightbown e Spada (1999) mencionam o termo "automatismo" para descrever essa teoria de aquisição de língua, isto é, a aquisição parte de processos naturais e automáticos. Segundo as autoras, Chomsky argumenta que o desenvolvimento da língua ocorre da mesma maneira como outras funções biológicas: andar, por exemplo. Em uma crítica ao behaviorismo, Chomsky não acredita que imitações ou formação de hábitos podem auxiliar na aquisição de uma língua; para ele, as crianças têm uma habilidade inata de compreender, sozinhas, o funcionamento de um determinado sistema linguístico (Lightbown e Spada, 1999).

\footnotetext{
${ }^{4}$ Para esse teórico (Skinner), sugerimos a leitura da síntese crítica proposta por Schultz D.P.; Schultz S.E. (1992) História da Psicologia Moderna. São Paulo: Cultrix.
} 
A teoria sócio-interacionista possui fundamentação em Bakhtin (1986) e em Vygotsky (1991), que concebiam a língua como um conjunto de expressões usadas por um povo - já abordando, assim, o conceito de cultura, ainda que implicitamente - e expressa por meio do discurso, em interações entre os falantes. Nesse sentido, a concepção de língua dessa teoria é visivelmente mais abrangente e contrária àquelas das teorias anteriores, contemplando a possibilidade da construção social do significado por meio da interação.

As três teorias citadas podem ser caracterizadas como as mais frequentes nas pesquisas em aquisição de línguas em $\mathrm{LA}^{5}$. Embora não tratem explicitamente do aprendizado de língua estrangeira ${ }^{6}$, seus postulados podem ser aplicados a esse ensino por tratarem de questões inerentes a língua e linguagem, nas quais se inserem as línguas não-maternas.

Portanto, acredito ser válido investigar a potencialidade de abordagem de aspectos culturais nas teorias de aquisição de linguagem mencionadas. Embora algumas não sejam amplamente recorrentes no momento contemporâneo, faz-se pertinente analisá-las e avaliá-las em relação às suas amplitudes, à possibilidade de abranger a compreensão do conceito de cultura no ensino e uso de LE.

Como aponta Almeida Filho (2005:21), “É preciso investigar sistematicamente qual o papel reservado para as línguas na escola e em que medida elas frustram pressupostos de aquisição". Assim, nos itens subsequentes, apresento os pressupostos envolvidos na aquisição, e eventuais lacunas, principalmente na capacidade para abrigar o ensino de aspectos culturais.

\section{A POSIÇÃO DA CULTURA NO BEHAVIORISMO}

Os estudos behavioristas exerceram influência nos estudos de aquisição de língua até a década de 60. A premissa dessa teoria, como já apontado anteriormente, consiste na visão da língua como um comportamento e, assim, passível de ser adquirida por meio de formação de hábitos.

\footnotetext{
${ }^{5}$ Essas são as teorias enfatizadas por Larsen-Freeman (2000), Richards e Rodgers (2001), Lightbown e Spada (1999), Anthony (1963), entre outros.

${ }^{6}$ Lightbown e Spada (1999) são enfáticas ao afirmar que Chomsky não fez nenhuma consideração específica sobre a teoria do inatismo no ensino de línguas estrangeiras: todas as suas reflexões se referem à língua materna. As autoras apontam, todavia, controvérsias entre estudiosos: alguns acreditam que a compreensão sobre o aprendizado da LE pode ser melhor se tomada a perspectiva do inatismo, ao passo que outros autores defendem a ideia de que essa teoria não é adequada para os processos de ensinoaprendizagem de outras línguas que não a materna.
} 
Segundo Lightbown e Spada (1999:23): "De acordo com behavioristas, todo aprendizado, seja ele verbal ou não-verbal, ocorre por meio do mesmo processo: formação de hábitos". Tal concepção corrobora o que tenho dito acerca do princípio behaviorista, e faz surgir indagações quanto aos seus alcances e à sua proposta de aquisição de língua.

Ao partir do pressuposto de que a criança adquire sua língua materna através de observações (primariamente inconscientes) e "análises silenciosas", por assim dizer, há uma associação possível entre a aquisição de língua com relativa passividade por parte do aprendiz.

Não há, ao que parece, nenhuma postura dessa doutrina que atribua à criança / aluno um papel ativo na aquisição de uma língua, seja ela materna ou não. A ênfase em imitações e observações de um "modelo do falante nativo" parece excluir a noção de tentativa, erro (que é condenado), questionamentos, deslizes gramaticais e atitude, que são comuns a qualquer criança que está começando a adquirir sua língua materna. Além disso, é pouco provável que existam crianças que invistam mais tempo em observar a fala de adultos do que usufruir de situações comunicativas para interagir e, partindo dessas interações, descobrir, ainda que inconscientemente, construções que são socialmente aceitáveis ou não.

Em se tratando de aprendizado de língua em sala de aula, a formação de hábitos proposta pelo behaviorismo soa pouco apropriada para o momento contemporâneo. A princípio, é difícil imaginar uma sala de aula em que comportamento passivo consiga conduzir o aprendiz a algum nível de sucesso na língua, já que, nesse sentido, a interação - e uso da língua - inevitavelmente fica em segundo plano.

Além disso, se assumirmos a noção de condicionamento de hábitos e reforços positivos que o behaviorismo prega, estamos preterindo a construção de significados sociais por meio da interação em prol unicamente do desenvolvimento da competência linguística do aluno. Nesse caso, isso tende a ocorrer por meio de exercícios estruturais, como repetição de modelos, por exemplo, focalizando apenas aspectos formais da língua. A avaliação das produções linguísticas do aprendiz é pautada somente no uso da forma, desprezando-se aspectos sociolinguísticos e discursivos.

Torna-se difícil imaginar, assim, como a orientação na cultura-alvo pode ser possível em uma teoria fundamentada na valorização da formação de hábitos por meio de exercícios de repetição que, muitas vezes, são mecânicos, e desconsideram o valor comunicativo inerente a qualquer língua. Ademais, a cultura de um povo está 
intrinsecamente ligada à sua linguagem, e é nas interações que mensagens são comunicadas. Nesse sentido, a conexão intrínseca entre cultura e linguagem parece distante de ser apreendida em uma teoria que prioriza a formação de hábitos em detrimento da construção de sentidos.

Para Bohn (2005:13): “Os estudos culturais indicam que é na linguagem que se constroem as diferenças constituintes da identidade humana". A limitação da teoria behaviorista reside, portanto, na dificuldade em propiciar ao aluno situações que possibilitem o uso da língua em contextos reais, situações em que diferenças inerentes à identidade humana possam surgir na linguagem, o que incitaria o aluno à reflexão e análise da mesma. Essa importante postura ativa do aprendiz parece distante dos preceitos behavioristas, tendo em vista o papel secundário atribuído à interação no processo de aprendizagem de uma LE.

Feitas essas considerações, a abordagem de questões culturais soa pouco possível em um método no qual a língua é tida como comportamento, pois sua complexidade e sua intrínseca relação com uma cadeia de eventos históricos, sociais e políticos não são exploradas; o aprendizado de estruturas linguísticas sobrepõe-se à comunicação significativa e relevante.

\section{CULTURA E INATISMO: UMA QUESTÃO DE IDENTIDADE}

No período pós-década de 60, a teoria inatista surge no cenário de pesquisas em aquisição de língua materna, tendo Chomsky (1969) como expoente principal, cuja concepção de aquisição diferia muito da vertente behaviorista. Ele não apenas a contestou (argumentando que a língua vai além do processo de formação de hábitos, atingindo um intrincado sistema de regras), mas também originou o "pensamento" inatista.

Segundo essa noção, a criança nasce com uma habilidade natural para a aquisição de uma língua. O ser-humano possui uma predisposição para atuar nas habilidades envolvidas na linguagem, o que, de imediato, distancia essa doutrina do pressuposto behaviorista.

Sobre essa questão, Lightbown e Spada (1999) afirmam:

Primeiramente, os aprendizes têm que prestar atenção a qualquer aspecto da língua que eles estão tentando entender ou produzir. Gradualmente, através da experiência e prática, os aprendizes se tornam capazes de usar certas partes de seu conhecimento 
tão rapidamente e automaticamente que não estão nem cientes de que o estão fazendo. ${ }^{7}$ (p. 25)

Embora o behaviorismo tenha sido contestado por teóricos inatistas, é possível depreender semelhanças entre ambas as teorias. Ao compreendermos que na teoria inatista o aprendiz deve inicialmente estar atento à produção linguística daqueles ao seu redor, atribui-se à criança (ou aluno) uma posição passiva no processo de aquisição de uma língua. A proficiência na língua, de acordo com as autoras citadas, é atingida por meio de "experiência" e "prática". Ainda que esses elementos possam representar caminhos válidos no desenvolvimento da aquisição de uma língua, eles parecem vagos no que diz respeito ao modo como essa proficiência seria, de fato, sistematicamente alcançada.

É importante ressaltar que concordamos que a prática e a vivência em uma determinada língua facilitam sua aquisição, especialmente em contextos de imersão. No entanto, no cenário de sala de aula, no qual as oportunidades de prática e vivência são notadamente reduzidas, como ocorre a aprendizagem pautada nos pressupostos inatistas? Qual deve ser a metodologia do professor para que a aprendizagem de LE seja bem-sucedida? Quanto e como deve ser a exposição dos alunos à língua-alvo para que eles consigam apreendê-la "naturalmente"? Considerando que essa teoria está sustentada na pressuposição da habilidade inata das pessoas, como lidar com os alunos que apresentam dificuldades de aprendizagem?

Essas perguntas apontam a fragilidade da teoria inatista no que tange ao processo de ensino-aprendizagem de LE. Reconheço que ela tem bases estruturadas na aquisição de língua materna, e é tida como "novata" nos estudos em LE, como apontam Lightbown e Spada (1999). Ainda assim, uma vez inserida no cenário de aprendizagem de línguas, pertence ao escopo da LA verificar sua abrangência em questões de uso de linguagem.

Assim, no caso da aprendizagem de LI como fruto de uma habilidade inata do aluno para o aprendizado de línguas, de que forma o ensino de cultura associada à língua-alvo ocorre nessa abordagem? Se o inatismo parte de um pressuposto semelhante ao do behaviorismo, isto é, a observação de "modelos", a inserção de questões culturais também parece improvável nessa concepção, uma vez que observar cultura consiste em

\footnotetext{
${ }^{7}$ Tradução nossa. "At first, learners have to pay attention to any aspect of language which they are trying to understand or produce. Gradually, through experience and practice, learners become able to use certain parts of their knowledge so quickly and automatically that they are not even aware that they are doing it."
} 
tarefa simplificadora e superficial, além de não garantir que os alunos compreendam aspectos significativos e não estereotípicos da cultura-alvo.

Além disso, atendo-me às principais características do inatismo, e considerando a relação indissociável entre língua e cultura, seria possível afirmar que as crianças têm, também, uma habilidade inata para adquirir cultura? Embora não possa negar que todos os seres humanos são seres culturais, passíveis de compreenderem e assimilarem culturas distintas, esses processos são mais complexos do que apenas a "observação" ou "prática"; eles são decorrentes das relações e interações sociais nas quais diferentes identidades são estabelecidas e representadas. Nesse sentido, vejo escassas possibilidades de orientação na cultura-alvo na teoria inatista, pois, ao contrário do que apontam concepções essencialistas, cultura e identidade não são "uma segunda natureza", não nascem e permanecem inertes ao longo do desenvolvimento do ser humano (Cuche, 2002).

Vale ressaltar, contudo, que, em situações de imersão, a teoria inatista pode ser capaz de abranger o ensino de questões culturais inerentes à língua que está ao redor. Nesse caso, a criança estaria envolvida integralmente com a língua que busca adquirir, tanto por meio de exposição ao insumo quanto por envolvimento em encontros interacionais que a imersão proporciona.

Embora acredite na possibilidade do sucesso do inatismo em situações de imersão, uma ressalva se faz necessária. Chomsky (1969) trata, em seus estudos, de um falante ideal. Remete, portanto, a uma homogeneidade que contempla a língua - como um sistema regular e estático - e não a fala, que também constitui objeto de estudo da linguística. Similarmente, em se tratando de problemas de uso de linguagem, a fala (atrelada à busca pela inteligibilidade e aos conflitos que tocam a língua) também é o objeto da Linguística Aplicada.

Dessa maneira, o inatismo torna-se pouco sistematizável para a realidade da sala de aula. É, também, uma teoria pouco passível de abranger cultura (em toda sua amplitude) especialmente considerando-se o contexto de ensino-aprendizado de LE no Brasil, ou seja, escolas de idiomas e regulares nas quais a "observação" estaria limitada apenas à figura do professor e a eventuais contatos com discursos orais e escritos, dentro ou fora da sala de aula.

Ao não mencionar a interação em sua abordagem, a teoria inatista parece ignorar o papel da cultura como parte integrante da construção identitária dos sujeitos, identidade essa expressa por meio da linguagem. 
O papel social de uma educação que se queira intercultural é oferecer aos alunos oportunidades de construir (e refletir criticamente sobre) sua identidade e a identidade do outro. Nesse sentido, a teoria inatista parece desconsiderar que a identidade é moldada quantitativamente e principalmente qualitativamente por meio de relações dialógicas, ou seja, não é uma essência que acompanha o sujeito desde o seu nascimento. É por meio de oportunidades de estimulação de atuação crítica em sala de aula - e não somente por meio da confiança na habilidade inata para aprender línguas que o aluno pode aprender a orientar-se na cultura-alvo e, concomitamente, produzir (ao invés de reproduzir) significados através da interação.

\title{
SÓCIO-INTERACIONISMO NO ATUAL CONTEXTO DE ENSINO- APRENDIZAGEM DE LI
}

Em contraposição às teorias de aquisição de línguas que enfatizavam a formação de hábitos (behaviorismo) ou a capacidade inata da criança (inatismo), a teoria sóciointeracionista pauta-se na existência da sociedade como elemento crucial para propiciar interação que, por sua vez, tornará possível a aquisição, como resultado da posição ativa da criança ou aluno em instâncias comunicativas.

Segundo Figueiredo (1997:24),

\begin{abstract}
Em síntese, na visão interacionista, a língua materna é vista como um produto da atividade social, determinado cultural e historicamente, e um processo de interação das crianças com os membros de sua comunidade. Ela não é uma forma de comportamento, nem tampouco uma faculdade inata que capacita as crianças a adquirir somente a competência linguística.
\end{abstract}

É notável, portanto, a distância entre o sócio-interacionismo e as teorias que o precederam. Segundo os princípios dessa teoria, a aquisição de uma língua é fruto da interação da criança com seu ambiente, e mais importante, da necessidade (que todo serhumano possui) de interação com os membros de uma determinada comunidade linguística. Assim, somente a competência linguística (Chomsky, 1969) não é suficiente para sustentar o falante em uma situação real; é preciso respaldo da competência comunicativa (Hymes, 1972), cujo foco está na comunicação em primeiro lugar.

Em se tratando de competência comunicativa, a ideia saliente é a de que apenas conhecimento sobre regras gramaticais não supre todas as necessidades do sujeito nas interações; ele deve saber quando e como utilizá-las para comunicar-se com eficácia. 
A noção de falante ideal defendida por Chomsky (1969), portanto, é refutada pelo sócio-interacionismo, no qual a língua não é tida como estática e homogênea; essa teoria consiste, portanto, em

(...)uma definição de linguagem como a apresentada por Bakhtin (2002), como produção de sentidos na interação social, portanto, não fixa, mas móvel, não homogênea, mas sempre marcada pela enunciação e portanto afetada pelos traços culturais do entorno social em que se realiza. (Bohn, 2005:19).

A ênfase na interação torna possível uma "abertura" à abordagem do conceito de cultura, como não havia ocorrido com as outras teorias estudadas neste artigo. Como aponta Bohn (2005), a comunidade na qual a criança ou aluno está inserido lhe permitirá compreender, por meio da comunicação, a cultura que subjaz a ela; esta, por sua vez, será expressa através da linguagem que nutre o discurso dessa sociedade. Observa-se, então, a noção de identidade como um conceito construído coletivamente e pautado pela língua, como diz Figueiredo (1997:23) ao parafrasear Bakhtin: “(...)a consideração da língua como criação coletiva”.

Em situação de imersão, é evidente que a aprendizagem de uma LE estará intimamente associada à cultura, uma vez que o aprendiz estará em constante contato com facetas típicas da sociedade-alvo. Em sala de aula, contudo, o contato do aluno com a cultura-alvo é consideravelmente menor e modificado, estabelecendo-se recortes através de músicas, filmes, livros, revistas e websites, que podem não ser fiéis à interação face-a-face.

Ainda assim, avalio que o sócio-interacionismo é a vertente mais consistente com a possibilidade de abordagem de cultura no ensino de LE (nesse caso, a LI).

Além da possibilidade de abordagem cultural no ensino de LI por meio dos veículos já mencionados, a posição do professor em sala de aula, como formador de opiniões, é essencial. Espera-se dele, assim como de todos os outros pilares que compõem o processo de ensino-aprendizagem de línguas ${ }^{8}$, uma postura crítica acerca do ensino de aspectos culturais e identitários associados aos falantes nativos de LI.

A sensibilização cultural dos estudantes no processo de ensino-aprendizagem de LE se torna um objetivo possível por meio de práticas que propiciem interações significativas entre aluno-professor e especialmente aluno-aluno. Nesse sentido, o sócio-interacionismo, fundamentando na premissa de que interações relevantes podem

\footnotetext{
8 Material didático; abordagem; metodologia; planejamento; avaliação - entre outros (Almeida Filho, 2005).
} 
fomentar o desenvolvimento na língua, parece permitir maiores oportunidades de aplicação de atividades indagadoras e provocadoras que, mediadas pelos pilares já citados anteriormente, levarão os estudantes à reflexão e ponderação de estereótipos sobre o outro e sobre si mesmos.

Em resumo, a lacuna existente nas teorias previamente discutidas consiste na pouca abertura ao ensino de cultura. No sócio-interacionismo, aspectos culturais podem ser discutidos em atividades que estimulem a interação e reflexão acerca da culturaalvo, como exercícios com filmes (que discutam estereótipos comumente retratados no cinema); debates sobre tópicos controversos sob o ponto de vista da comunidade da língua-alvo; atividades em grupos cujo objetivo seja, por meio do desenvolvimento da capacidade de argumentação, analisar estilos de vida diferentes; entre outras.

\section{CONSIDERAÇÕES FINAIS}

A posição da língua inglesa no atual momento sócio-histórico caracteriza-se por forte importância em diversos cenários: negociações econômicas / sociais / políticas envolvendo pessoas de diferentes países; intercâmbio científico de profissionais e pesquisadores provindos de diversos locais do mundo; além da própria sala de aula, na qual a existência de várias culturas é frequente, mesmo que todos os alunos presentes possuam a mesma nacionalidade (Kawachi, 2011).

Dessa forma, a língua inglesa não é somente o idioma majoritariamente utilizado ao redor do mundo, mas também é aquele que está associado ao poder de países dominantes (principalmente Estados Unidos e Inglaterra) no contexto de relações políticas e sociais da pós-modernidade que vivemos.

Isso aponta, portanto, a necessidade e relevância da investigação acerca de aspectos culturais no processo de ensino-aprendizagem da LI. Neste artigo, busquei relacionar a possibilidade de sensibilização cultural no ensino da LI com as principais teorias de aquisição de linguagem em ensino de LE.

No percurso de investigação das teorias de aquisição de linguagem, teci algumas considerações sobre as noções behaviorista, inatista e sócio-interacionista, bem como a abrangência delas de modo a tornar o ensino de cultura possível no ensino de LE (LI, nesse caso).

Tendo em mente que cultura jamais deve ser negligenciada ao aluno - pois permite compreender aspectos intricados e sutis da língua-alvo que se está aprendendo, 
e o coloca em contato, por meio da interação, com sua própria cultura - avaliei, na concepção behavorista, pouca abertura ao tratamento de questões culturais.

A fundamentação dessa teoria na criação de hábitos por meio da "imitação" permite pouco espaço para a inserção de cultura em sala de aula, uma vez que ensinar o aluno a observar a cultura é tarefa pouco palpável e dificilmente concebível. Exercícios de repetição estruturalistas (bastante comuns à teoria behaviorista) distanciam-se do contexto real de uso da língua-alvo, isto é, situações comunicativas nas quais, possivelmente, o aluno se deparará com problemas de linguagem muitas vezes originados de diferenças culturais.

Existem, portanto, na concepção behaviorista, lacunas em relação a possibilidades para interação do aluno, tanto com pessoas fora de sua sala de aula quanto com outros alunos do/no mesmo contexto. A importância de encontros interacionais deve ser enfatizada, pois eles propiciam o contato com diferentes pontos de vista, diferentes culturas, como afirma Tannen (1986:08).: “(...) toda comunicação é mais ou menos intercultural".

$\mathrm{Na}$ teoria inatista, está em foco a capacidade inata da criança para adquirir língua, capacidade essa que deve ser desenvolvida por meio de observações da línguaalvo e, gradualmente, por meio de ajustes às hipóteses construídas na etapa de observação. Essa exposição à língua-alvo se refere, nessa teoria, à língua, e não à fala, o que denota a abordagem de um falante ideal.

Embora essa teoria tenha sido originada a partir da necessidade do estudo de aquisição de língua materna, no ensino de LE o inatismo não é sistematizável, pois o falante ideal refere-se a uma situação hipotética, e não a um contexto real de comunicação.

Há, em ambas as teorias, poucas oportunidades para estimular uma posição ativa do aluno, motivando-o a atuar interativamente de modo a produzir na / a língua-alvo e, por meio de suas produções, entrar em contato com diferentes culturas.

Tanto a concepção behaviorista quanto a inatista parecem fincar bases na idéia de língua como instância individual, quando, na verdade, ainda que possa representar individualidades e diferenças, é socialmente construída, desenvolve-se continuamente por meio da interação, e é delineada em uma coletividade culturalmente rica. Como aponta Tannen (1984): “O estilo individual de cada pessoa é uma combinação de 
características aprendidas em interações com outras pessoas (portanto, social) além de características desenvolvidas idiossincraticamente." ${ }^{\prime 9}$ (p. 10).

A teoria sócio-interacionista, por sua vez, renova expectativas das anteriores no que se refere à possibilidade de abordar cultura nas aulas de LE. Essa teoria atende a premissa de refletir sobre cultura no ensino de LI pautando-se na ideia de que a língua não é um comportamento, tampouco uma produção das faculdades inatas do aluno, mas sim fruto da interação social entre pessoas de uma mesma (ou não) comunidade.

Não argumento, aqui, que essa teoria desconsidere o ensino de pontos linguísticos em favor de questões culturais. Analiso que características intrínsecas a cada povo devem ser apresentadas ao aluno por meio de interações sociais, e não por meio de imagens pré-concebidas de culturas que invariavelmente resultam na criação e propagação de estereótipos.

Espera-se que, associado à orientação teórica mais apropriada (como, nesse trabalho, classificamos a sócio-interacionista), o processo de ensino-aprendizagem de LE contemple criticidade de maneira a desenvolver um aluno não somente apto a repetir modelos ou observar regras, mas também crítico o bastante para compreender culturas diferentes da sua como simplesmente distintas, evitando, assim, estereótipos culturais.

É importante ressaltar que, embora algumas das teorias estudadas refiram-se à aquisição de língua materna, há, atualmente, pesquisas adaptando-as ao ensino de LE. Por isso, acreditamos que elas podem ser vistas como teorias de aprendizado de LE, pois lidam com a linguagem e problemas que dela podem decorrer. Segundo Cavalcanti (1986), “(...) a visão de LE deve ser ampliada para que o equacionamento seja não ao nível do ensino de línguas, mas ao nível de questões de uso da linguagem na escola ou em um contexto social mais amplo" (p. 09).

Como afirma Cavalcanti (1986), o importante é conceber a linguagem como presente não somente em sala de aula, mas em contextos mais amplos, como as situações de interação intercultural já citadas neste trabalho (âmbitos político, social, etc). Nesses contextos, o uso da linguagem deve ser observado para que, com auxílio do corpo teórico da LA, seja possível problematizar mal-entendidos frequentes em instâncias comunicativas.

Os desvendamentos de problemas de linguagem na comunicação serão mais frequentes e significativos se os pressupostos culturais dos interlocutores na interação

\footnotetext{
${ }^{9}$ Tradução nossa. "Each person's individual style is a combination of features learned in interaction with others (hence, social) plus features developed idiosyncratically."
} 
forem levados em consideração, estabelecendo-se, assim, a cultura da LE como passível de estudos, de ser vista como diferente, e não como recorte fragmentado e estereotipado, como comumente ocorre nas aulas de LE.

\section{REFERÊNCIAS}

Almeida Filho, J.C.P. (2005) Lingüística Aplicada - Ensino de Línguas e Comunicação. Campinas: Pontes Editora.

Bakhtin, M. (1986) Marxismo e filosofia da linguagem. São Paulo: Hucitec.

Barbosa, L.M.A. (2009) Visões interculturais ou identidades cristalizadas? O Brasil e os brasileiros nos livros didáticos de português para estrangeiros. In: Fleuri, R.M.(Org.). XII Congresso da Associaçao Internacional para pesquisa Intercultural (ARIC). 1-18, Florianópolis: ARIC - Association Internationale pour la Recherche Interculturelle, v. 1.

Bohn, H.I. (2005) As exigências da pós-modernidade sobre a pesquisa em linguística aplicada no Brasil. In: Freire, M.M.; Abrahão, M.H.V. \& Barcelos, A.M.F. (orgs.). Linguística aplicada \& contemporaneidade. 11-23. Campinas: Pontes Editores.

Bolognini, C.Z. (1998) Relações de contato: a questão da cultura. In Trabalhos em Linguística Aplicada. 7-14. Campinas: UNICAMP.

Canagarajah, R. (1999) Resisting linguistic imperialism in English Teaching. Oxford: Oxford University Press.

Cavalcanti, M. C. (1986) A propósito de Linguística Aplicada. In: Trabalhos Lingüística Aplicada. 5-12. Campinas: UNICAMP, vol. 7.

Chomsky, N. (1969) Linguistics and Philosophy. In: Hook, S. (org.). Language and philosophy. New York Univ. Press, 1969

Cuche, D. (2002) A Noção de Cultura nas Ciências Sociais. Tradução de Ribeiro, V. Bauru: EDUSC.

Da Matta, R (1983). Relativizando: Uma introdução à Antropologia Social. Petrópolis: Editora Vozes.

. (1994) O que faz o brasil, Brasil? Rio de Janeiro: Rocco.

Figueiredo, F.J.Q. (1997) Aprendendo com os Erros - Uma perspectiva comunicativa de ensino de línguas. Goiânia: Editora UFG.

Hymes, D.H. (1972) On Communicative Competence. In: Pride, J.B. \& J.Holmes (eds.) Sociolinguistic.Middlesex: Penguin Books, 1972.

Kawachi, G.J. (2011) Estereótipos culturais em estágios avançados de aprendizado de inglês como língua estrangeira e seus desdobramentos para ensino e uso do idioma. 
Dissertação (Mestrado em Linguística) - Universidade Federal de São Carlos, São Carlos.

Larsen-Freeman, D. (2000) Techniques and principles in language teaching. Oxford: Oxford University Press.

Lightbown, P.M.; Spada, N. (1999) How languages are Learned. Oxford University Press.

Moita Lopes, L. P. (1996) Oficina de Lingüística Aplicada: A natureza social e educacional dos processos de ensino/aprendizagem de línguas. Campinas: Mercado de Letras.

Richards, J. \& Rodgers, T. (1982) Approaches and methods in language teaching. Cambridge: Cambridge University Press.

Schultz D.P., Schultz S.E. História da Psicologia Moderna. São Paulo: Cultrix, 1992

Tannen, D. (1984) Conversational Style: Analyzing Talk Among Friends. Georgetown University.

(1986) That's not what I meant! How Conversational Style Makes or Breaks Your Relations with Others. New York: William Morrow and Company, Inc.

Vygotsky, L. S. (1991) Pensamento e Linguagem. Tradução de Jéferson Luís Camargo. São Paulo: Martins Fontes.

\section{O AUTOR}

Guilherme Jotto Kawachi é licenciado em Letras - Português/Inglês pela Universidade Federal de São Carlos (UFSCar), e mestre em Linguística pela mesma universidade. Atualmente, é doutorando em Linguística Aplicada pela Universidade Estadual de Campinas (Unicamp). Já foi professor de inglês em uma universidade, em escolas de idiomas e, mais recentemente, na rede pública do Estado de São Paulo. Seu foco de interesse incide sobre o estudo de questões (inter)culturais no ensinoaprendizagem de LI.

E-mail: guilhermejk@hotmail.com 